\title{
SERUM CHANGES FOLLOWING PROTEIN "SHOCK" THERAPY*
}

\author{
WILLIAM F. PETERSEN, M.D.
}

CHICAGO

The degree of interest with which certain phases of therapeusis along nonspecific lines has been received would seem to indicate that clinical observation of such character must have been quite frequently, although the possible significance had escaped comment. Various German clinicians have, in recent times, emphasized the striking therapeutic effects achieved with this so-called "protein" therapy, a not inapt designation, conveying, as it does, not only the concept of the basic reacting agent, but implying, too, wide range of effectiveness as a therapeutic measure. The best results have undoubtedly been obtained in the arthritic processes, an extended series of observations on such cases having been published by Miller and Lusk, ${ }^{1}$ and Culver. ${ }^{2}$ They seem particularly favorable for treatment, because the contraindications are few and the objective and subjective evidence of improvement under treatment are directly observable.

In a paper published last year Jobling ${ }^{3}$ discussed some of the factors that were possibly operative following intravenous protein therapy, basing his views on an extended study in experimental animals. The changes in the blood pressure and the blood cytology have been studied by Scully in Miller's Clinic, and inasmuch as Culver ${ }^{5}$ has followed the changes in antibody formation, these phases are not covered in this paper, which is limited to the study of certain ferment and physical alterations following protein injections.

When the normal or diseased organism is. subjected to a protein shock of whatsoever origin - bacterial, protein split products, milk, etc. - certain fundamental but as yet intangible alterations occur in the organism, as a result of which an increased resistance to infection

* Submitted for publication June 25, 1917.

* From the Medical Clinic of Joseph L. Miller at the Cook County Hospi. tal and the Laboratory of Physiologic Chemistry, College of Medicine Uni.. versity of Illinois.

1. Miller, J. L., and Lusk, F.: The Use of Foreign Protein in the Treat. ment of Arthritis, Jour. Am. Med. Assn., 1916, 67, 2010.

2. Culver, H.: The Treatment of Gonorrheal Infections, Jour. Am. Med. Assn., 1917, 68, 362.

3. Jobling, J. W., and Petersen, W. F.: The Nonspecific Factors in the Treat. ment of Disease, Jour. Am. Med. Assn., 1916, 66, 1753.

4. Scully, F. J.: Jour. Am. Med. Assn., 1917, 69, 20.

5. Culver, H.: Jour. Lab. and Clin. Med., October, 1917, 2. 
and to intoxication is definitely established. The terms "antianaphylaxis" and "desensitization" applied to this state convey certain ideas of specificity and are therefore not quite suited; the German "umstimmung" possibly expresses the fundamental character of the changes involved, and von Groer ${ }^{6}$ has coined the term "ergotropie" to cover the new therapeutic conception whereby we seek to change the reactivity of the host through a biologic reaction rather than directly to alter or destroy the invading parasite.

In its essentials, the state of antianaphylaxis, or the refractory period following anaphylactic shock, is found to occur after all varietie. of protein shock. Vaughan ${ }^{\top}$ noted this resistance following the injection of his protein split products; Zinsser and Dwyer ${ }^{8}$ have discussed it in its relation to proteophylatoxin or anaphylatoxin; Jobling ${ }^{9}$ observed it to occur after serotoxin injections and Tigue and $\mathrm{McWilliams}{ }^{10}$ have recently observed the increased resistance to typhoid infection in rabbits after a typhoid vaccine shock. It has been known for some time, of course, that antianaphylaxis is relatively nonspecific, insofar as following recovery from a nonfatal shock dose in a doubly sensitized animal the sensitization to the second antigen is greatly reduced. Bessau $^{11}$ and his associates have fully discussed this subject. Inasmuch as the "ergotropie" observed in these newer therapeutic studies is also nonspecific, its relation to the antianaphylactic condition is at least made probable.

In a series of studies made some time ago, Jobling ${ }^{12}$ and his associates found that anaphylactic shock (and the protein intoxications in general) was accompanied in dogs by marked changes in the blood ferment-antiferment balance. . It seemed warranted to assume that, at least in such animals, the shock involved both cellular and humoral factors; that the cellular reaction was probably the primary one, and that the serum reactions that followed brought about further intoxication and death. It was observed that during shock a condition obtained (low antiferment and increased protease) when proteolytic activity was favored, while following shock the reverse held true (increased antiferment and low protease). During this refractory period reinjection is followed by no change in the ferment-antiferment balance. Rusznjak ${ }^{13}$ was the first to observe the change in the antiferment, and

6. von Groer: München, med. Wchnschr., 1915, 62, 1312.

7. Vaughan, V. C.: Protein Split Products, 1913, Lea \& Febiger, Philadelphia and New York.

8. Zinsser, H., and Dwyer, J. A.: Jour. Exper. Med., 1914, 20, 387.

9. Jobling and Petersen: Jour. Exper. Med., 1914, 19, 480.

10. Tigue, O., and McWilliams, H.: Jour. Immunol., 1917,'2, 167.

11. Bessau, G., Opitz and Preusse, O.: Zentralbl. f. Bakt., Part 1, Orig., 1914. 74, 162 and 310 .

12. Jobling, Petersen and Eggstein: Jour. Exper. Med., 1915, 22, 401.

13. Rusznjak, S.: Deutsch. med. Wchnschr., 1912, 38, 168. 
suggested its possible significance in the phenomena of resistance following shock.

Friedberger and his school have developed the ideas originally presented by Matthes, and by Vaughan in this country, concerning the relation of fever to protein intoxication. According to this conception, which is based on a vast accumulation of experimental evidence, the invading organisms themselves, unless they happen to excrete a definite toxin, cause no marked intoxication of the host until the host becomes sensitized to the bacterial protein derived from disintegrated organisms. This state is ushered in by the febrile reaction. Freedom from symptoms could then occur either $(a)$ when the host is desensitized, or $(b)$ when the parasites are destroyed; it is clear that the first supposition need not imply the destruction of the infecting organisms. Unfortunately, in this relatively simple conception another factor is manifest, namely, that from the bacteria are derived not only native proteins that sensitize the host, but protein split products as well, which are able to intoxicate the host directly. During the refractory period the resistance to these is also increased, but the chief agent in ridding the system of this poison would be proteolytic ferments of the peptidase or ereptase type, which would hydrolyze these toxic products to the lowest and nontoxic form. From these considerations it is apparent that if in typhoid fever, for instance, protein shock is induced and the disease terminated by crisis, the infecting organism need not be destroyed, the host may be simply desensitized so that the condition in a manner resembles the period of incubation during which time organisms may be abundantly present, but cause no reaction. That this is actually the case is indicated in several reports from German workers who have obtained positive blood cultures and stool cultures in typhoids a considerable period of time after all disease manifestations had subsided following intravenous shock therapy; the patients being afebrile, the spleen small and the diazo reaction negative.

With these considerations in mind, it would seem pertinent to ascertain just what changes do occur in the serum of patients following protein therapy and in how far such changes may account for the therapeutic benefit derived.

\section{EXPERIMENTAL}

The serum changes studied included the following:

(a) Stalagmometric

(b) Concentration of serum (total nitrogen)

(c) Noncolloidal nitrogen of serum

(d) Antiferment

(e) Serum protease. (Chloroform method at 47 C.)

(f) Serum ereptase. (Peptone splitting at $47 \mathrm{C}$., tryptophan reaction)

(g) Serum diastase (Wohlgemuth method)

(h) Serum esterase (Michaelis-Rona and ethyl butyrate methods) 
The proteins injected were either typhoid bacilli in doses varying from 25 to 150 million (fresh vaccine) or albumoses; primary and secondary proteoses fractionated from Witte peptone. The latter, in doses from 40 to $60 \mathrm{mg}$. give a satisfactory reaction. The protocols selected are representative of the changes observed in a large series of cases.

(a) As a result of the peripheral vasodilation and the profuse sweating that normally follows protein shock, appreciable changes occur in the concentration of the blood serum, which in turn is reflected in the rate of the flow through the stalagmometer, as shown in the following determination:

J. P. Monarticular rheumatism. Typhoid vaccine injection.

Rate of flow before injection......... 12.8 drops per minute Rate of flow 2 hours after injection... 12.0 drops per minute Rate of flow 8 hours after injection... 11.4 drops per minute Rate of flow 24 hours after injection... 10.6 drops per minute Rate of flow 72 hours after injection... 11.3 drops per minute

(b) The concentration of the serum proteins is increased following the injections; for comparison the corresponding stalagmometric readings are shown together with the Kjeldahl titration for 2 c.c. of serum.

J. B. Acute arthritis. Typhoid vaccine injection.

\section{Stalagmometric Readings}

$\begin{array}{rr}\text { Before injection } \ldots \ldots \ldots . . & 10.7 \text { drops } \\ 3 \text { hours after injection.... } & 10.0 \text { drops } \\ 6 \text { hours after injection.... } & 9.3 \text { drops }\end{array}$

18 hours after injection.... 9.2 drops
Fifth Normal Hydrochloric Acid, Kjeldahl Titration for 2 C.c. Serum $\begin{array}{ll}6.2 & \text { c.c. } \\ 6.27 & \text { c.c. } \\ 6.5 & \text { c.c. } \\ 6.975 & \text { c.c. }\end{array}$

The change in the stalagmometer readings must depend largely in this case on the alteration of the concentration of the serum which may be of sufficient magnitude to mask smaller changes that might be expected to result from changes due to alterations of the dispersion of the serum colloids.

(c) The nonprotein nitrogen of the serum remains practically unaltered, as shown in the following two cases:

H. L. Acute arthritis and pharyngitis. R. C. Acute arthritis, with possible endocarditis; both received typhoid vaccine intravenously.

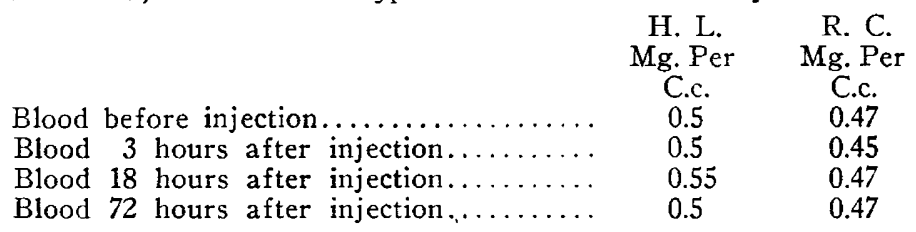

It is evident that no retention of nonprotein nitrogen takes place as a result of possible injury to the cells of the excretory apparatus, which coincides with the urinary examination made on cases following protein shock; that is, no albuminuria occurred unless already present before the injections and in these cases no increase in the amount of albumin was noted.

(d) The changes in the antiferment of the blood serum are usually well marked and quite uniform in the cases that react favorably to the shock therapy. Chart 1, A illustrates the changes taking place for a three-day period of observation in a case with complete recovery from an acute arthritis following intravenous injection of $60 \mathrm{mg}$. of a primary proteose. The persistence of the increased antiferment titer may be much less in duration, as shown in the second Chart 1,B. This case, K.H., was one of multiple subacute arthritis which did not improve to any marked extent after injection of typhoid vaccines, although there was temporary relief. 
Finally, the cases that show no permanent improvement seldom show any increase in the antiferment, indeed almost always present a decrease in the titer following the shock, as illustrated in the third and fourth charts, $1, \mathrm{C}$. and $1, D$.

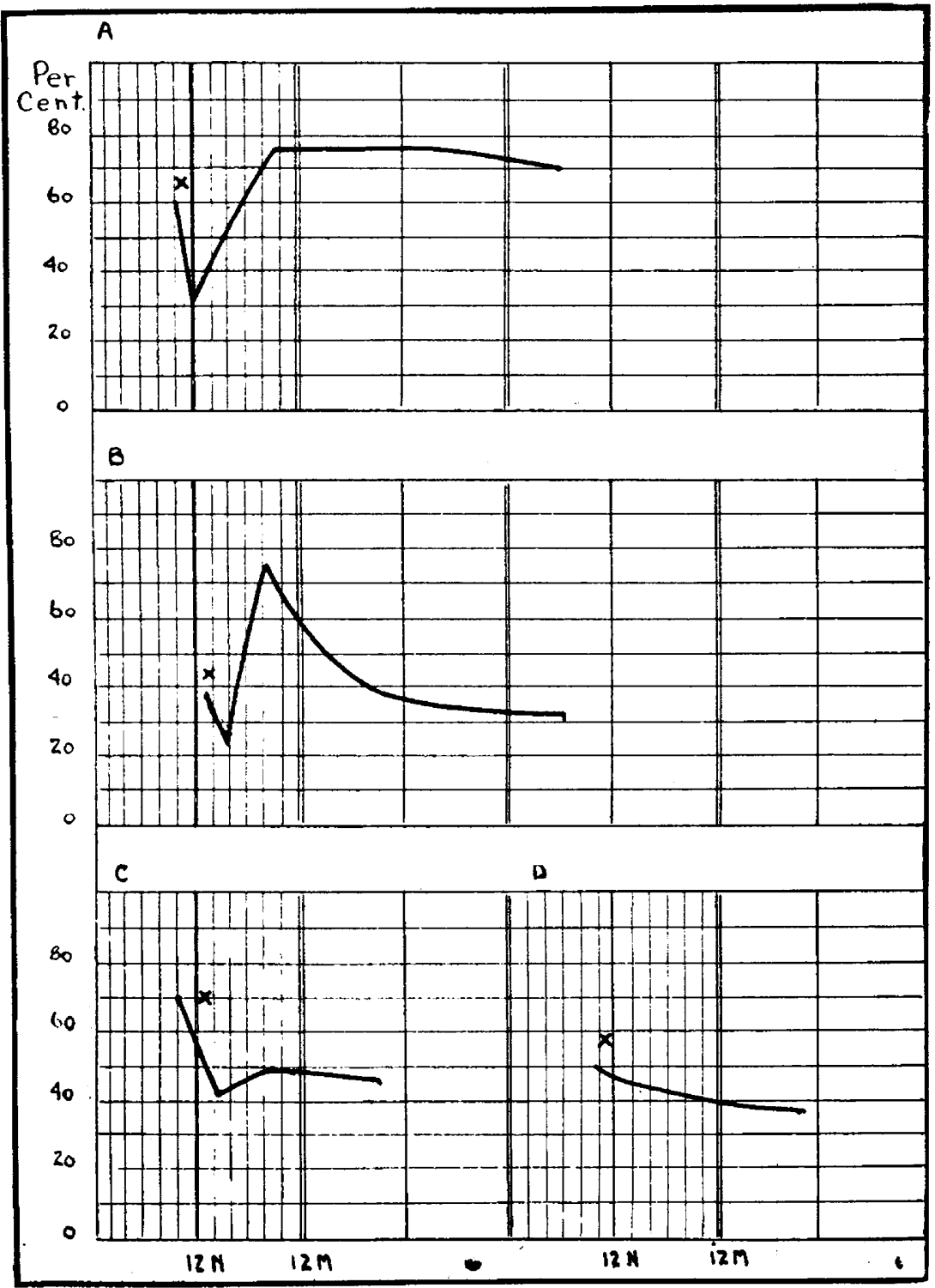

Fig. 1.-Changes in antiferment titer following protein shock. $X$ indicates injection.

(e) The serum protease is almost invariably decreased immediately following the shock, but later increases progressively for a period of two or three days, as shown in the following tabulations in which the titer of the ferment 
is expressed in the amount of serum protein digested in 1 c.c. at $47 \mathrm{C}$. when emulsified with chloroform. The titer for the first eighteen hours following injection in an acute arthritis, G. W., with complete recovery, was as follows:

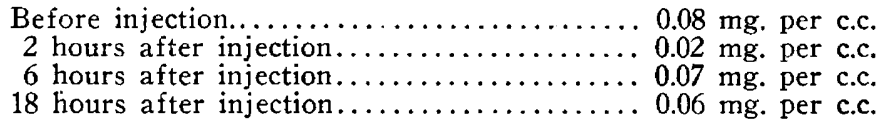

H. L. Acute arthritis; typhoid vaccine.

Protease before injection.............. None demonstrable

Protease 3 hours after injection......... None demonstrable

Protease 18 hours after injection........ $0.03 \mathrm{mg}$. per c.c.

Protease 48 hours after injection........ $0.2 \mathrm{mg}$. per c.c.

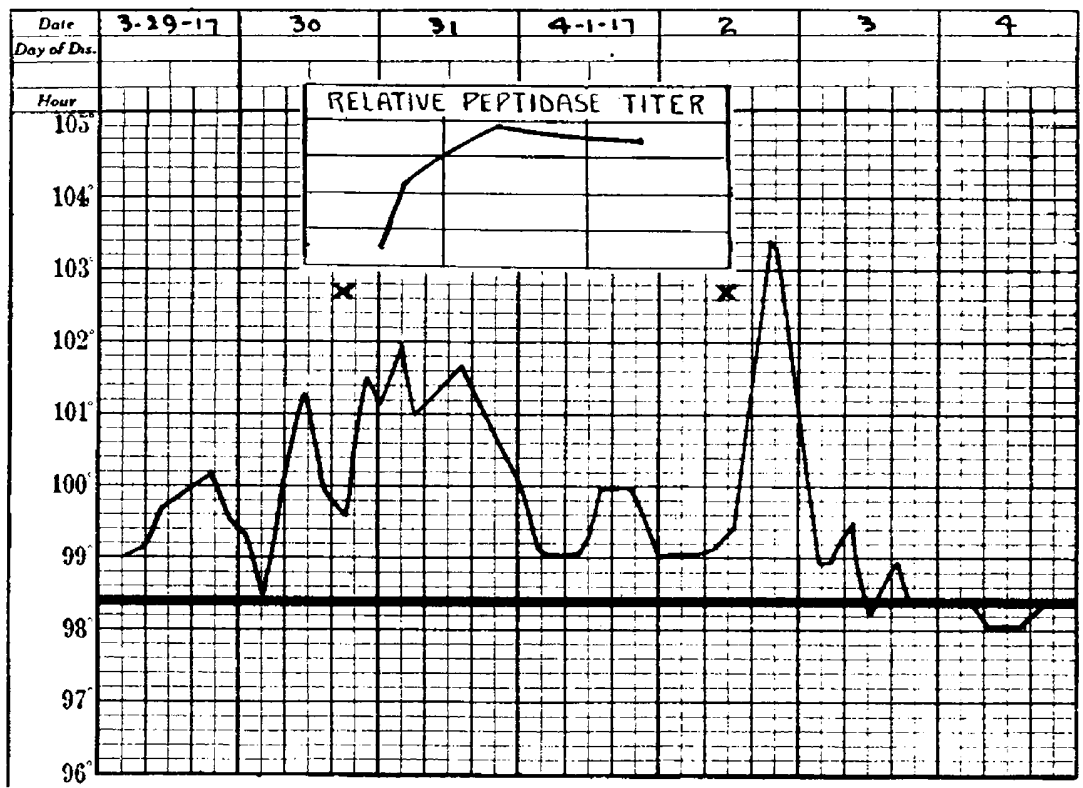

Chart 2.-Peptidase titer following protein shock. $X$ indicates injection.

(f) The serum ereptase or peptidase is almost invariably increased in those cases that respond to vaccines with clinical improvement, the maximum concentration being reached after twenty-four hours.

J. C., white man, with physical findings of diffuse bronchitis, had persistent irregular temperature for the two weeks he was under observation, with no signs of improvement. Two doses of typhoid vaccine were given intravenously, following which marked clinical improvement occurred, together with clearing of physical findings and an afebrile temperature curve. The relative peptidase titer observed in the serum following the second dose of vaccine is illustrated in Chart 2.

A. G. Multiple acute arthritis. Typhoid vaccine was administered, with complete recovery. The peptidase titer in this case was as follows:

Before injection ...........

6 hours after injection.....

24 hours after injection....

\begin{tabular}{cccc}
\hline 0.5 C.c. & 0.25 C.c. & 0.125 C.c. & 0.0625 C.c. \\
+++ & +++ & + & - \\
++++ & ++++ & + & - \\
++++ & ++++ & ++ & +
\end{tabular}


The majority of cases that show no clinical improvement give no evidence of an increase in peptidase; this is illustrated in the following patient:

J. S. Gonorrheal rheumatism (knees and ankles) of several months' duration, with subacute prostatitis. Three c.c. 2 per cent. proteose was injected, resulting in well marked reaction but no clinical improvement.

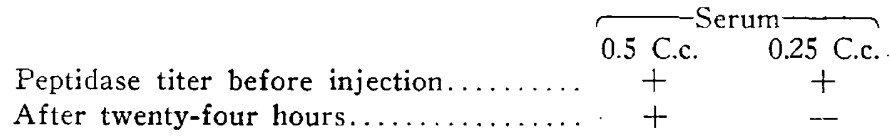

There being no clinical improvement, the patient was given three injections of typhoid vaccine without benefit. Gonococcus vaccine was then tried, without effect. The patient was relieved to a greater extent by iodids given intravenously than with any other measure, but did not make a complete recovery until he had developed an intercurrent peritonsillar abscess, following which the joint symptoms cleared completely.

( $g$ ) Diastatic activity. This ferment is almost invariably diminished after the shock and the titer may remain low for several days thereafter.

J. P. Monarticular arthritis.
Diastatic titer before injection.
$\mathrm{D} \frac{37^{\circ}}{24 \cdot \mathrm{Hrs}}=32$
3 hours after injection................ D $=16$
6 hours after injection................ D $\quad=16$
18 hours after injection................ D $\quad=8$

(h) The study of the lipolytic activity (esterase titer) revealed no consistent alterations.

\section{RESISTANCE TO REINJECTION}

When the patient is subjected to two or more doses of vaccine intravenously, evidences of resistance are occasionally noted, not only against the shock effect -chill, fever and sweating-but also to some extent against further beneficial effect. It is our impression that the maximum benefit to the patient follows the first injection, although undoubtedly a number of cases will show continued improvement with reinjections when the primary injection did not completely clear up the disease. The resistance which develops is nonspecific in character, as illustrated in the following case:

C. H. Acute multiple arthritis. He received at intervals three doses of typhoid vaccine, each from fifty to seventy-five million, intravenously. The patient was improved, but still complained of some stiffness of the ankles. At this time it was observed that the injection of a dose of the same amount was followed by no reaction. The serum examination made at this time showed a relátively high antiferment titer- 0.01 c.c. of serum inhibiting 80 per cent. of the trypsin unit; ereptase was present in a moderate amount, 0.125 c.c. serum giving a good tryptophan reaction in twenty-four hours' digestion at $47 \mathrm{C}$.; and the serum contained protease- $-0.08 \mathrm{mg}$. digestion per cubic centimeter in twenty-four hours at $47 \mathrm{C}$. These changes, while definite, were, however, identical with those observed in cases not resistant to reinjection; so that we are forced to conclude that the resistance must be largely cellular in character.

\section{DISCUSSION}

From the observations described it is evident that the reaction of the host which follows protein shock therapy is accompanied by definite serum changes, including a mobilization of both protease and ereptase, 
alterations in the antiferment titer, as well as certain physical changes. It is to be emphasized that these changes are not to be considered as wholly responsible for the therapentic effect observed following shock therapy; indeed, we are under the impression that they should be regarded rather as an index of cellular changes which are the primary ones concerned; but inasmuch as the means of investigation of direct cellular changes are limited, the serum changes may be considered as offering at least some tangible object for study. Culver has recently followed the antibody changes following intravenous vaccine therapy. He finds an increase in the specific bacteriolysin and opsonin (gonococcus) following injections of gonococcus vaccines (as well as proteoses), an increase most marked after the first injection; with subsequent injections a decrease may be observed, despite continued improvement of the patient. Practically the same may be said of the proteolytic serum ferments. A mobilization takes place after the injection, but following injections may be followed by no such change. On the other hand, the cases that do not show clinical improvement seldom show an increase in peptidase, thus differing from the antibody observations. The ereptase may be considered a detoxicating agent which aids in the elimination of the toxic products of the pathogenic organism, while the antibody mobilization may be responsible for the actual destruction of these organisms.

The mobilization of the ferments is much less prompt than in experimental animals, nor is it directly proportional to the severity of the chill or the degree of the temperature reaction, although as a rule the clinical improvement is more apparent when a good febrile reaction is elicited.

It is of course well known that the thorough sweating of a patient will of itself afford marked relief of arthritic symptoms, but relief is practically always transient. It is probable that the immediate relief which follows shock therapy in these cases is due to a similar cause, the difference lying in the permanancy of the cure. It is reasonable to suppose that in this the mobilization of the leukocytes and antibodies and ferments is of importance.

The changes in the antiferment have been discussed previously; following the initial decrease a rise takes place which in the favorable cases persists for from two to seven days, while in the cases that show no clinical improvement the increase has been found to be transient or to be lacking altogether.

As will be discussed in a following paper, an increased antiferment titer is commonly associated with an increased resistance to protein intoxication, the increase either itself protecting the cells or at least being indicative of cellular changes associated with an increased resist- 
ance. Whether there exists a possible direct relation to bacterial proliferation is a question that has not as yet been thoroughly studied. Wright $^{14}$ has carried out some experiments along this line, but his investigations were concerned chiefly with the bacterial flora of wounds and the relation of the leukoproteolytic ferments and antiferment thereto.

Tigue and McWilliams ${ }^{15}$ have suggested that the therapeutic effect may depend on an increased passage of antibody containing serum into the lymph channels. In experimental animals Davis and $\mathrm{I}^{16}$ have, indeed, found that a marked augmentation of the flow from the thoracic duct does occur following shock, so that the suggestion is one that may have considerable bearing on the subject.

We believe it is at present justifiable to consider that the benefits of shock therapy do not depend on any single alteration in the reacting organism, but on a series of factors in which not only the serum antibody and ferment changes, but the leukocytosis, the fever and sweating and the increased lymph flow have a part along with the important cellular changes which are as yet intangible.

14. Wright, A.: Brit. Med. Jour., 1915, 2, 629.

15. Tigue and McWilliams: Jour. Immunol., 1917, 2, 193.

16. Davis, B. F., and Petersen, W. F.: Jour. Exper. Med., 1917, 26. 